Code: P-29

\title{
INSTRUCTIONAL DESIGN OF INTEGRATION FACTOR BASED ON RECIPROCAL TEACHING APPROACH
}

\author{
Misdalina \\ PGRI University of Palembang \\ misdalina68@ymail.com
}

\begin{abstract}
Conventional learning are given by lecturer, make the students passive and just receive the new knowledge without a meaningful thingking process. Therefore it is required an instructional design, which invites students to understand the knowledge of their own efforts through Reciprocal Teaching approach. The method which used in this study is the research design method that include: preparing for the experiment, experimenting in the classroom, and retrospective analysis. Learning is designed for two meetings. Data collecting is made by documentation, field notes, and tests. The results is Hypothetical Learning Trajectory (HLT) for the material integration factor based on Reciprocal Teaching approach.
\end{abstract}

Keywords: Reciprocal Teaching, learning design

\section{INTRODUCTION}

One of the sub material of differential equations course is integration factor. Integration factor is a function to be determined an inexact differential equation into an exact differential equation. To find the integration factor, students are invited to be active in learning. All this time, the conventional learning are given by lecturer, make the students passive and just receive the new knowledge without a meaningful thingking process. Therefore it is required an instructional design that invites students to understand the knowledge of their own efforts through Reciprocal Teaching approach.

The Reciprocal Teaching approach is reversed teaching. This approach is well suited for candidate teachers, because all the activities in the Reciprocal Teaching can practice the skills in presenting learning materials. According to Allen (in Foster and Rotoloni, 2005) Reciprocal Teaching is learning groups based on a shared learning experience to reveal the thinking of students through natural dialogue models. Students are encouraged to build their confidence through collaborative meaning between teachers and students, thus leading to high quality learning. According to Palincsar, Brown, and Campione 1989 (in Orey, 2001), Reciprocal Teaching is a dialogue between teachers and students, who describe reciprocal because each student respond to each other, through the clarification strategies, predictions, ask questions, and make a summary. This can happen because through Reciprocal Teaching, students in receiving the material on its own efforts, through metacognitive skills. As described by Suyanto, Reciprocal Teaching approach is a teaching based on asking questions through metacognitive skills are taught through direct instruction and modeling by the faculty to improve student reading performance who 
is low reading comprehension (Suyanto, 2009). Furthermore students develop these skills on their own efforts with encouragement, support, and a scaffolding system (Trianto, 2007). Based on the above opinions it can be concluded that the Reciprocal Teaching approach is reversed teaching, which is done in groups through direct teaching and modeling lecturers through four strategies, namely clarification, predictions, ask questions, and make a summary.

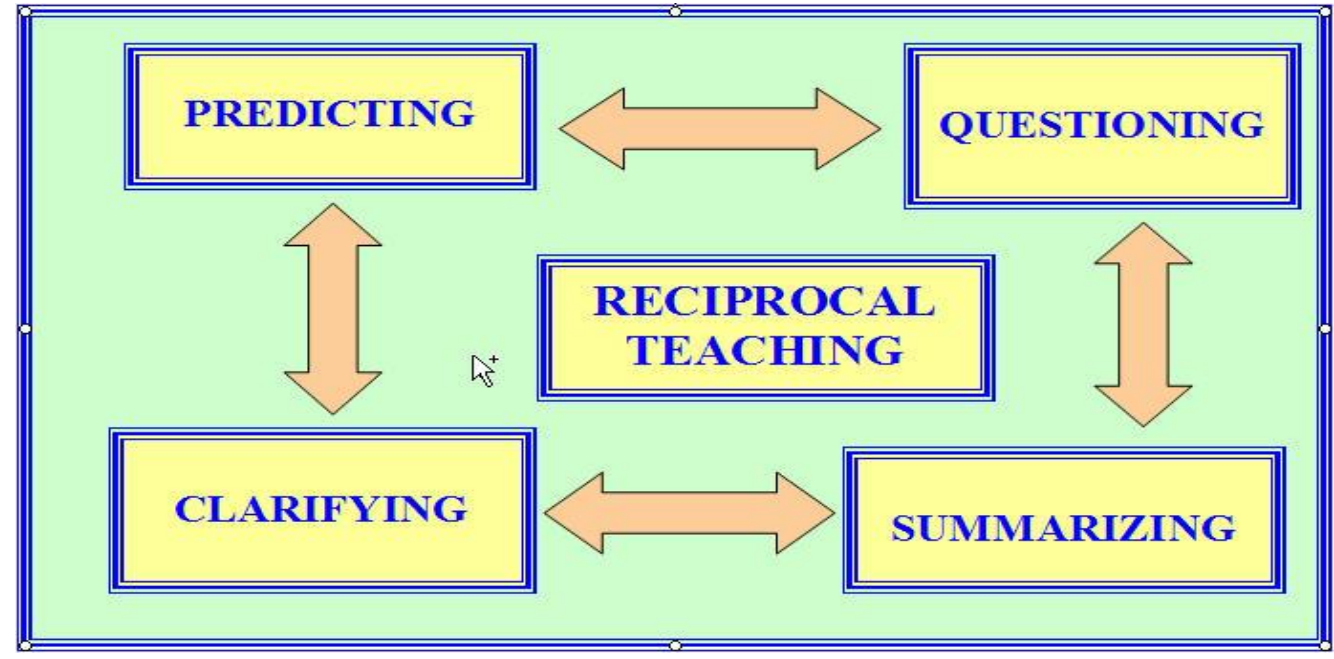

Figure 1. Illustration of reciprocal teaching approach (Foster and Rotoloni, 2005)

Based on the description that has been stated above, the problem of this research is how is the learning design of integrating factor based on Reciprocal Teaching approach? This research aims to produce HLT for integration factors material based on Reciprocal Teaching approach.

The method in this study is Design Research. Design Research (Akker, 2006: 19) include: preparing for the experiment, experimenting in the classroom, and retrospective analysis.

The stage of preparing for the experiment, consisting of preliminary design and pilot experiment. Preliminary design is done through the study of theory and design HLT. Theoretical study on the material of integration factors relating to the the exact equations material. Then, prediction is formed in the learning process. Furthermore designed HLT, to design sequences of predictions about strategies, ideas, and ways of students' thinking. While the pilot experiment, which is the bridge between the stage of the preliminary and the stage of taching experiment, with the aim of teaching stage examines students' initial abilities and adjustment with HLT (Kesumawati, 2011).

The stage of experimenting in the classroom is collecting data to produce HLT to integration factors material based on Reciprocal Teaching approach. Implementation is designed for 2 (two) times meetings with time to face is for 150 minutes each meeting. The Subjects of this study is the fourth semester students of Mathematics Faculty of Teacher Education Program University of PGRI Palembang. Techniques of data collection through the documentation, field notes, and tests.

Next, on stage of retrospective analysis, is as the creation and transformation of information after HLT tested. There are four activities were analyzed: analysis in clarification oriented activities, analysis in prediction activities oriented, analysis in 
ask activity oriented, and analysis in recent summarizes activities. Data analysis techniques through descriptive analysis.

\section{MAIN SECTION}

This research results HLT to analysis integration factor material based on Reciprocal Teaching approach. At HLT design stage, the reading text of integration factor material was made in advance.

\section{First meeting:}

\section{Integration Factor}

Definition: A multiplier factor that makes an inexact differential equation into an exact differential equation is called an integrating factor.

For example, differential equations $\left(2 x y d x+\left(2 x^{2}+3\right) d y=0\right.$ not exact. If the equation is multiplied by y equation this is produce $2 x y^{2} d x+\left(2 x^{2} y+3 y\right) d y=0$. This last equation is the exact differential equation (test). Defining multiplier factor y is called an integrating factor.

Example 1: $\quad$ Solve the differential equation $\left(2 x y d x+\left(2 x^{2}+3\right) d y=0\right.$

\section{Completion:}

Above has been stated that this differential equation has a factor of integration $y$. Differential equations derived from multiplying the above equation with integration factor is $2 \mathrm{xy}^{2} \mathrm{dx}+\left(2 \mathrm{x}^{2} \mathrm{y}+3 \mathrm{y}\right) \mathrm{dy}=0$.

First of all functions declared $M(x, y)=2 x y^{2}$ and $N(x, y)=\left(2 x^{2} y+3 y\right)$, therefore $\frac{\partial}{\partial y} \mathrm{M}(\mathrm{x}, \mathrm{y})=4 \mathrm{xy}$ dan $\frac{\partial}{\partial x} \mathrm{~N}(\mathrm{x}, \mathrm{y})=4 \mathrm{xy}$

In this case the differential equation is exact.

\section{Determine Integration Factor}

In the previous discussion has revealed that the integration factor is a function that can lead to inexact differential equations $M(x, y) d x+N(x, y) d y=0 \quad 2.7)$ to be exact. The function we let $\mathrm{u}(\mathrm{x}, \mathrm{y})$ as a factor of integration. The purpose of this study is to determine the function of $u$ such that $M(x, y) d x+N(x, y) d y=0$ to be exact. Based on the differential equation: $\mathrm{u}(\mathrm{x}, \mathrm{y}) \mathrm{M}(\mathrm{x}, \mathrm{y}) \mathrm{dx}+\mathrm{u}(\mathrm{x}, \mathrm{y}) \mathrm{N}(\mathrm{x}, \mathrm{y}) \mathrm{dy}=0 \quad$ (2.8) is an exact differential equation. Therefore the theorem is obtained:

$$
\begin{aligned}
& \frac{\partial}{\partial y} \mathrm{u}(\mathrm{x}, \mathrm{y}) \mathrm{M}(\mathrm{x}, \mathrm{y})=\frac{\partial}{\partial x} \mathrm{u}(\mathrm{x}, \mathrm{y}) \mathrm{N}(\mathrm{x}, \mathrm{y}) \\
& \mathrm{u}(\mathrm{x}, \mathrm{y}) \cdot \frac{\partial}{\partial y} \mathrm{M}(\mathrm{x}, \mathrm{y})+\mathrm{M}(\mathrm{x}, \mathrm{y}) \cdot \frac{\partial}{\partial y} \mathrm{u}(\mathrm{x}, \mathrm{y})=\mathrm{u}(\mathrm{x}, \mathrm{y}) \frac{\partial}{\partial x} \mathrm{~N}(\mathrm{x}, \mathrm{y})+\mathrm{N}(\mathrm{x}, \mathrm{y}) \cdot \frac{\partial}{\partial x} \mathrm{u}(\mathrm{x}, \mathrm{y}) \\
& \mathrm{u}(\mathrm{x}, \mathrm{y}) \cdot \frac{\partial}{\partial y} \mathrm{M}(\mathrm{x}, \mathrm{y})-\mathrm{u}(\mathrm{x}, \mathrm{y}) \cdot \frac{\partial}{\partial x} \mathrm{~N}(\mathrm{x}, \mathrm{y})=-\mathrm{M}(\mathrm{x}, \mathrm{y}) \frac{\partial}{\partial y} \mathrm{u}(\mathrm{x}, \mathrm{y})+\mathrm{N}(\mathrm{x}, \mathrm{y}) \cdot \frac{\partial}{\partial x} \mathrm{u}(\mathrm{x}, \mathrm{y}) \\
& \mathrm{u}(\mathrm{x}, \mathrm{y})\left(\frac{\partial}{\partial y} \mathrm{M}(\mathrm{x}, \mathrm{y})-\frac{\partial}{\partial x} \mathrm{~N}(\mathrm{x}, \mathrm{y})\right)=-\left(\mathrm{M}(\mathrm{x}, \mathrm{y}) \cdot \frac{\partial}{\partial y} \mathrm{u}(\mathrm{x}, \mathrm{y})-\mathrm{N}(\mathrm{x}, \mathrm{y}) \cdot \frac{\partial}{\partial x} \mathrm{u}(\mathrm{x}, \mathrm{y})\right.
\end{aligned}
$$




$$
u=\frac{-\left(M(x, y) \cdot \frac{\partial}{\partial y} u(x, y)-N \frac{\partial}{\partial x} u(x, y)\right)}{\left(\frac{\partial}{\partial y} M(x, y)-\frac{\partial}{\partial x}(N(x, y)\right.}
$$

Next will be reviewed the types of the function u itself.

\section{U only function of $x$ alone}

For the case $\mathrm{u}(\mathrm{x}, \mathrm{y})=\mathrm{u}(\mathrm{x})$, with $\frac{\partial}{\partial y} \mathrm{u}(\mathrm{x})=0$ and $\frac{\partial}{\partial x} \mathrm{u}(\mathrm{x})=\frac{d u(x)}{d x}$ be obtained

$$
\mathrm{u}(\mathrm{x})=\frac{N(x, y)}{\frac{\partial}{\partial y} M(x, y)-\frac{\partial}{\partial x} N(x, y)} \frac{d u(x)}{d x}
$$

The above equation can be written in the form $\frac{d u(x)}{u(x)}=\frac{\frac{\partial}{\partial y} M(x, y)-\frac{\partial}{\partial x} N(x, y)}{N(x, y)} \mathrm{dx}$, $\ln \mathrm{u}(\mathrm{x})=\int \frac{\frac{\partial}{\partial y} M(x, y)-\frac{\partial}{\partial x} N(x, y)}{N} \mathrm{dx}$

equation (2.11) if the note on the left side and the right is a function of $\mathrm{x}$ only. Now suppose that the coefficient of $\mathrm{dx}$ is $\mathrm{F}(\mathrm{x})$, with $\mathrm{F}(\mathrm{x})=\frac{\frac{\partial}{\partial y} M(x, y)-\frac{\partial}{\partial x} N(x, y)}{N}$

if $\mathrm{u}(\mathrm{x})=e^{\int F(x) d x}$, then $\ln \mathrm{u}(\mathrm{x})=\int F(x) d x$, so that equation (2.11) can be expressed:

$\mathrm{u}(\mathrm{X})=e^{\int F(x) d x}$.

Integrating factor of the differential equation (2.8) is the result of the integration of the right hand side of equation (2.13)

Example 2: Show that the differential equation

$$
\left(4 x y+3 y^{2}-x\right) d x+x(x+2 y) d y=0
$$

Is not an exact differential equation and then determine the integration factor!

Completion:

First of all functions declared $M(x, y)=4 x y+3 y^{2}-x$

and $\mathrm{N}(\mathrm{x}, \mathrm{y})=\mathrm{x}(\mathrm{x}+2 \mathrm{y})$, therefore

$$
\frac{\partial}{\partial y} M(x, y)=4 x+6 y \text { dan } \frac{\partial}{\partial x} N(x, y)=2 x+2 y
$$

In this case the differential equation (2.14) is not exact because the differential results are not the same and u can be searched through 


$$
\mathrm{F}(\mathrm{x})=\frac{\frac{\partial}{\partial y} M(x, y)-\frac{\partial}{\partial x} N(x, y)}{N}=\frac{2}{x}
$$

By using (2.13) obtained by the integration factor of equation (2.14) is

$u(x)=x^{2}$

\section{U only function of y alone}

For the case $\mathrm{u}(\mathrm{x}, \mathrm{y})=\mathrm{u}(\mathrm{y})$, with $\frac{\partial}{\partial y} \mathrm{u}(\mathrm{y})=\frac{d u(y)}{d y}$ and $\frac{\partial}{\partial x} \mathrm{u}(\mathrm{y})=0 \quad$ be obtained, $\mathrm{u}(\mathrm{y})=\frac{-M(x, y)}{\frac{\partial}{\partial y} M(x, y)-\frac{\partial}{\partial x} N(x, y)} \frac{d u(y)}{d y}$

The above equation can be written in the form $\frac{d u(y)}{u(y)}=-\frac{\frac{\partial}{\partial y} M(x, y)-\frac{\partial}{\partial x} N(x, y)}{M} \mathrm{dy}$

$$
\ln \mathrm{u}(\mathrm{y})=\int-\frac{\frac{\partial}{\partial y} M(x, y)-\frac{\partial}{\partial x} N(x, y)}{M} \mathrm{dy}
$$

equation (2.23) if the note on the left side and the right is a function of $y$ alone. Now suppose that the coefficient of dy is $G(y)$,

with $\mathrm{G}(\mathrm{y})=\frac{\frac{\partial}{\partial y} M(x, y)-\frac{\partial}{\partial x} N(x, y)}{M}$

if $\mathrm{u}(\mathrm{y})=e^{-\int G(y) d y}$, then $\ln \mathrm{u}(\mathrm{y})=-\int G(y) d y$, so that equation (2.22) can be expressed: $\mathrm{u}(\mathrm{y})=e^{-\int G(y) d y}$

Integrating factor of the differential equation (2.8) is the result of the integration of the right hand side of equation (2.25)

Example 3: Show that the differential equation

$$
y(x+y+1) d x+x(x+3 y+2) d y=0
$$

is not an exact differential equation and then determine the integration factor!

Completion:

First of all functions declared $M(x, y)=x y+y^{2}+y$

and $N(x, y)=x^{2}+3 x y+2 x$, therefore

$$
\frac{\partial}{\partial y} M(x, y)=x+2 y+1 \text { dan } \frac{\partial}{\partial x} N(x, y)=2 x+3 y+2
$$

In this case the differential equation (2.26) is not exact and 


$$
\mathrm{G}(\mathrm{y})=\frac{\frac{\partial}{\partial y} M(x, y)-\frac{\partial}{\partial x} N(x, y)}{M}=\frac{1}{y}
$$

By using (2.25) obtained by the integration factor of equation (2.26) is

$$
\mathrm{u}(\mathrm{y})=\mathrm{y}
$$

\section{The second meeting:}

\section{U function of $x$ and $y$}

For the case $\mathrm{u}(\mathrm{x}, \mathrm{y})=\mathrm{u}(\mathrm{v})$, with $\frac{\partial}{\partial y} \mathrm{u}(\mathrm{x}, \mathrm{y})=\frac{\partial v}{\partial y} \cdot \frac{d u}{d v}$

and $\frac{\partial}{\partial x} \mathrm{u}(\mathrm{x}, \mathrm{y})=\frac{\partial v}{\partial x} \cdot \frac{d u}{d v}, 0$ be obtained

$\mathrm{u}(\mathrm{x}, \mathrm{y})=\frac{-\left(M \frac{\partial v}{\partial y}-N \frac{\partial v}{\partial x}\right)}{\left(\frac{\partial}{\partial y} M(x, y)-\frac{\partial}{\partial x} N(x, y)\right.} \cdot \frac{d u}{d v}$

The above equation can be written in the form

$$
\begin{gathered}
\frac{d u}{u}=-\frac{\frac{\partial}{\partial y} M(x, y)-\frac{\partial}{\partial x} N(x, y)}{M(x, y) \frac{\partial_{v}}{\partial y}-N(x, y) \frac{\partial_{v}}{\partial x}} \mathrm{dv} \\
\ln \mathrm{u}(\mathrm{x}, \mathrm{y})=\int-\frac{\frac{\partial}{\partial y} M(x, y)-\frac{\partial}{\partial x} N(x, y)}{M(x, y) \frac{\partial_{v}}{\partial y}-N(x, y) \frac{\partial_{v}}{\partial x}} \mathrm{dv}
\end{gathered}
$$

equation (2:36) if the note on the left side and the right is a function of $\mathrm{x}$ and $\mathrm{y}$. Now suppose that the coefficient of $d v$ is $H(v)$ is,

with $\mathrm{H}(\mathrm{v})=\frac{\frac{\partial}{\partial y} M(x, y)-\frac{\partial}{\partial x} N(x, y)}{M(x, y) \frac{\partial_{v}}{\partial y}-N(x, y) \frac{\partial_{v}}{\partial x}}$

if $\mathrm{u}(\mathrm{x}, \mathrm{y})=e^{-\int H(v) d v}$, then $\ln \mathrm{u}(\mathrm{x}, \mathrm{y})=-\int H(v) d v$, so that equation $(2: 36)$ can be expressed: $\mathrm{u}(\mathrm{x}, \mathrm{y})=e^{-\int H(v) d v}$

Integrating factor of the differential equation (2.8) is the result of the integration of the right hand side of equation $(2: 37)$ 
Example: Show that the differential equation

$\left(5 x^{2} y+y^{3}\right) d x+\left(5 x y^{2}+x^{3}\right) d y=0$

is not an exact differential equations and integration factor has a function of the form $x^{2}+y^{2}$. Determine the factor of integration!

Completion:

First of all functions declared $M(x, y)=5 x^{2} y+y^{3}$

and $N(x, y)=5 x y^{2}+x^{3}$, therefore

$\frac{\partial}{\partial y} M(x, y)=5 x^{2}+3 y^{2}$

$\frac{\partial}{\partial x} \mathrm{~N}(\mathrm{x}, \mathrm{y})=5 \mathrm{y}^{2}+3 \mathrm{x}^{2}$

In this case by (2.39) and (2.40) the differential equation (2.38) is not exact and the form $\mathrm{v}(\mathrm{x}, \mathrm{y})=\mathrm{x}^{2}+\mathrm{y}^{2}$ have:

$\frac{\partial v}{\partial y}=2 \mathrm{y} ; \frac{\partial v}{\partial x}=2 \mathrm{x}$

$M \frac{\partial v}{\partial y}-N \frac{\partial v}{\partial x}=2\left(\mathrm{y}^{4}-\mathrm{x}^{4}\right)$

by (2:42), can be calculated (2.37)

$\mathrm{H}(\mathrm{v})=\frac{\frac{\partial}{\partial y} M(x, y)-\frac{\partial}{\partial x} N(x, y)}{M(x, y) \frac{\partial_{v}}{\partial y}-N(x, y) \frac{\partial_{v}}{\partial x}}=\frac{1}{x^{2}+y^{2}}$

By using (2:43) integration factor obtained from equation (2:38) is

$\mathrm{u}(\mathrm{y})=\mathrm{x}^{2}+\mathrm{y}^{2}$

There are several forms of factor $\mathrm{x}$ and $\mathrm{y}$ integration functions, among others:

$\mathrm{v}=\mathrm{x}^{2}+\mathrm{y}^{2} ; \mathrm{v}=\mathrm{x}+\mathrm{y} ; \mathrm{v}=\mathrm{x}-\mathrm{y} ; \mathrm{v}=\mathrm{x} \cdot \mathrm{y}$

To $v=x^{2}+y^{2}$,

be obtained $\frac{\partial_{v}}{\partial y}=2 \mathrm{y} ; \frac{\partial v}{\partial x}=2 \mathrm{x}$, so that $\mathrm{u}(\mathrm{x}, \mathrm{y})=e^{-\int H(v) d v}$, with

$\mathrm{H}(\mathrm{v})=\frac{\frac{\partial}{\partial y} M(x, y)-\frac{\partial}{\partial x} N(x, y)}{M(x, y) \frac{\partial_{v}}{\partial y}-N(x, y) \frac{\partial_{\nu}}{\partial x}}=\frac{\frac{\partial}{\partial y} M(x, y)-\frac{\partial}{\partial x} N(x, y)}{M(x, y) 2 y-N(x, y) 2 x}$

- Show that the differential equation

$\left(2 x^{3} y^{2}-y\right) d x+\left(2 x^{2} y^{3}-x\right) d y=0$

is not an exact differential equations and integration factor has a function of the form xy. Determine the factor of integration! 
Completion:

First of all functions declared $M(x, y)=2 x^{3} y^{2}-y$

and $N(x, y)=2 x^{2} y^{3}-x$, therefore

$\frac{\partial}{\partial y} M(x, y)=4 x^{3} y-1$

$\frac{\partial}{\partial x} \mathrm{~N}(\mathrm{x}, \mathrm{y})=4 \mathrm{xy}^{3}-1$

In this case by (2:46) and (2:47) differential equations (2:45) and the inexact

$\frac{\partial}{\partial y} \mathrm{M}(\mathrm{x}, \mathrm{y})-\frac{\partial}{\partial x} \mathrm{~N}(\mathrm{x}, \mathrm{y})=4 \mathrm{xy}\left(\mathrm{x}^{2}-\mathrm{y}^{2}\right)$

form $v(x, y)=x y$ have :

$\frac{\partial v}{\partial y}=\mathrm{x} ; \frac{\partial v}{\partial x}=\mathrm{y}$

$M \frac{\partial v}{\partial y}-N \frac{\partial v}{\partial x}=2 \mathrm{x}^{2} \mathrm{y}^{2}\left(\mathrm{x}^{2}-\mathrm{y}^{2}\right)$

by (2:48) and (2:50), can be calculated (2:37)

$\mathrm{H}(\mathrm{v})=\frac{\frac{\partial}{\partial y} M(x, y)-\frac{\partial}{\partial x} N(x, y)}{M(x, y) \frac{\partial_{v}}{\partial y}-N(x, y) \frac{\partial_{v}}{\partial x}}=\frac{2}{x y}$

By using (2.51) is obtained from the integration factor equation (2.45)

is $\mathrm{u}(\mathrm{y})=\frac{1}{x^{2} y^{2}}$

The next, is designed student activities designed with four activities: clarification, predictions, ask questions, and make a summary.

First meeting:

Activity 1: Clarification

Goals: 1. Defining factor of integration

2. Looking for determining stages of the integration factor

Based on the reading text above, answer the question below:

1. In your opinion what is integration factor mean?

2. How the stages to determine integration factor? Describe it.

3. What functions that can be determined from the integration factor?

\section{Activity 2: Prediction}

Goals: determining factor of integration

1. Based on whether the integration factor of integration factor the form $x$ only or y only function can be determined?

2. Determine the factor of integration of $y(1+x y) d x-x d y=0$ 


\section{Activity 3: Question-Asking}

Objective: to monitor and evaluate the extent of reading material understanding. Give some questions to our self to crosscheck about what has been obtained from the learning process and what has not mastered of the whole concept!

1. What steps can I take to determine the factor of integration?

2. What is the easiest concept and most elusive of integration factor?

3. Is my answer is correct? How do I get to know the truth of an answer?

\section{Activity 4: Creating Summary}

Goal: to make a summary of the material studied

Make an overview of the learning process that goes along with the results using their own language, in accordance with the following questions:

1. What new concepts learned in the integration factor?

2. Explain the concepts with your own language?

\section{Second meeting:}

\section{Activity 1: clarification}

Goals: Looking for a common form of integration factor as function $\mathrm{x}$ and $\mathrm{y}$

Based on the reading text above, answer the question below:

1. How is the general form of $u$ integration factor as function of $x$ and $y$ ?

2. If $v=x^{2}+y^{2}$, then how is the general form of $u$ integration factor?

\section{Activity2: Prediction}

Goals: determining factor of integration

1. If $v=x+y$, then how is the general form of factor of integration $u$ ?

2. If $v=x-y$, then how is the general form of factor of integration $u$ ?

3. If $v=x . y$, then how is the general form of factor of integration $u$ ?

4. Determine the factor of integration of $\left(y^{3}-2 x^{2} y\right) d x+\left(2 x y^{2}-x^{3}\right) d y=0$

\section{Activity 3: Question-Asking}

Objective: to monitor and evaluate the extent of the reading materials understanding.

Give some questions to our self to crosscheck about what has been obtained from the learning process and what has not mastered of the whole concept!

1. What are the form of integration factor of functions $x$ and $y$, that is in the text passage above?

2. How to determine the proper integration factor of such form factors integration?

\section{Activity 4: Creating Summary}

Goal: to make a summary of the material studied

Make an overview of the learning process that goes along with the results using their own language, in accordance with the following questions:

1. How is the general form factor for integration $u$ function of $x$ and $y$ ?

2. If $v=x^{2}+y^{2}$, How then are the general form of factor of integration $u$ ?

3. If $v=x+y$, then how is the general form of factor of integration $u$ ?

4. If $v=x-y$, then how is the general form of factor of integration $u$ ?

5. If $v=x . y$, then how is the general form of factor of integration $u$ ? 


\section{Analysis of Clarification Activity}

Clarification activity, invite students to understand the reading material, which is then explained in accordance with the questions that have been prepared by lecturer. This activity is expected to occur on a reciprocal dialogue between students, and respond to each other, based on their reading comprehension.

The first results of the meeting, several students take turns explaining to the class, but there are students who do not understand the text reading, it appears that a student has not been unusual to try to understand the text itself because by the time the normal reading is always informed by lecturer. Reading text designed to allow students to find the formula of integration factor $\mathrm{x}$ or $\mathrm{y}$, which is already provide in the text reading, but long writing notation apparently affecting their visual (reading text will be revised). In the second meeting, students can give the explaination.

\section{Analysis of Prediction Activity}

In the prediction activities, students are invited to figure out the right answers to question that had been prepared by the lecturer.

Prediction activity results, at the first meeting, students can predict, but there is also a mistake (due to the lack of prior knowledge held, among others, the ability to determine derivatives and integrals). Students can use a formula in reading text, but have not been able to determine the factor of integration of $\mathrm{x}$ functions only or $\mathrm{y}$ function only. While in the second meeting, students are able to predict the number one up to three question quickly. But require rather long time to solve the number four.

\section{Analysis of Ask Activity}

Ask activity, giving students the opportunity to perform a cross-section, of what has been obtained from the learning process and what is has not been yet to master.

Results of the activities asked at the first meeting, students can explain the stages to determine of integration factor, however, questioned how strategi to determine factor integration of $\mathrm{x}$ function only or $\mathrm{y}$ function only. One of the students, trying to respond to how to determine the right strategy for determining the integration factor, but it still does not work. Here then the dialogue between students and faculty, by providing direction / guidance to find the right strategy. While in the second meeting, the students know the shape $v$ variations of the integration factor, but still confused shape $\mathrm{v}$ variations which one to choose. Here then the dialogue between students and faculty, by providing direction / guidance to find the right shape $\mathrm{v}$ variations. Based on the results of this activity asks, reading text will be revised to clarify the determining factor for the integration strategy.

\section{Analysis of Summarizes Activity}

Next, in the summarizing activity, students are invited to summarize the materials being studied by using their own language.

The summarize activities on the first meeting, students are still confused by the instructions in the HLT, so that the results of students' summary are not correct. Sentence orders, to encapsulate the material has not been specipik. So it needs to be revised HLT to summarize the activities. While in the second meeting, the order to 
summarize the material has specipik, so that students have appropriate summary of the results.

Results of the use of HLT for the Integration factor material based on Reciprocal Teaching approach is a very enthusiastic the students learn with the group, explaining each other, answer, ask, and can summarize the material in their own language student. It can be seen from classroom teaching and learning activities and document the results of student work. HLT revised in the reading text, with regard to notation and explanations, as well as the integration factor determining the strategy guide summarizes activities. Then at the end of the meeting, a test is gives to determine student comprehension. The results of tests given to students each meeting to the average student test results are 79 included in either category.

\section{CONCLUSION}

Based on the above results it can be concluded that the integration of instructional design factors such as Reciprocal Teaching approach based HLT containing text readings, and activities clarification, prediction, questioning, and summarizing.

HLT trial results at two meetings for integration factor material based on Reciprocal Teaching approach is a very enthusiastic the students learn with the group, explaining each other, answer, ask, and can summarize the material in their own language. At the first meeting, the students have not been accustomed to using the reciprocal teaching approach, especially on the activity of clarification. But in the second meeting, of students began diligently and trying to appear to explain to the class. While based on given test result in the end of the meeting, an average of 79 included in either category.

\section{REFERENCES}

Akker, J. V. (2006). Educational Design Research. London and New York: Routledge.

Foster, E., \& Rotoloni, B. (2005). Reciprocal teaching: General overview of theories. in $M$. Orey (Ed), Emerging perspectives on learning, teaching, and technology. Retrieved Desember 18, 2011, from Association for Educational Communications and Technology: http://projects.coe.uga.edu/epltt/index.php?title=Reciprocal_Teaching

Kesumawati, N. (2011). Desain Pembelajaran Luas Permukaan Bola Melalui Konteks Lampion Menggunakan Pendekatan PMRI di Kelas IX SMP. MIPMIPA, MIPA Education , 52-61.

Orey, M. (Ed).(2001). Emerging perspectives on learning, teaching, and technology. Retrieved Desember 18, 2011, from Association for Educational Communications and Technology: http://projects.coe.uga.edu/epltt/

Suyatno. (2009). Menjelajah Pembelajaran Inovatif. Surabaya: Mas Media Buana Pustaka.

Trianto. (2007). Model-model pembelajaran inovatif berorientasi kontrukstivisme. Jakarta: Prestasi Pustaka. 